\title{
Outdoor Air Pollution and Gestational Diabetes Mellitus: A Systematic Review and Meta-Analysis
}

\author{
*Mohamed H. ELSHAHIDI \\ Faculty of Medicine, Mansoura University, Mansoura, Dakabliya, Egypt \\ *Correspondence: Email: mohamedelshihidi@students.mans.edu.eg
}

(Received 07 Aug 2017; accepted 11 Feb 2018)

\begin{abstract}
Background: During the past 20 years, the prevalence of gestational diabetes mellitus (GDM) has increased by $\sim 10 \%-100 \%$ in several race/ethnicity groups. There is an association between ambient air pollution (AAP) and GDM. This study aimed to summarize the evidence about the association between AAP and GDM.

Methods: PubMed, Embase, Scopus, Web of Science and Cochrane Library were searched from inception till Oct 2017. Studies about the association between ambient air pollutants levels and GDM were included. Pooled effect estimates and their 95\% confidence interval (CI) were calculated using $\mathrm{R}$.

Results: Eight studies met the inclusion criteria. The odds of developing GDM upon exposure to CO (per 1 ppm), NO (per 1 ppb), NO2 (per $10 \mu \mathrm{g} / \mathrm{m} 3$ ), NOx (per 1 ppb), O3 (per 10 ppb), SO2 (per 10 ppb), PM10 (per $10 \mu \mathrm{g} / \mathrm{m} 3$ ) and PM2.5 (per $10 \mu \mathrm{g} / \mathrm{m} 3$ ) were 1.47 (95\% CI 0.88-2.06), 1.04 (95\% CI 1.03-1.06), 1 (95\% CI 0.931.08), 1.02 (95\% CI 1-1.04), 1.05 (95\% CI 0.94-1.16), 1.39 (95\% CI 1.04-1.73), 0.97 (95\% CI 0.94-0.99) and 1.12 (95\% CI 0.93-1.31), respectively.

Conclusion: The current literature showed evidence for an association between AAP and GDM. However, further well-designed studies are needed.
\end{abstract}

Keywords: Gestational diabetes; Air pollution; Pregnancy; Complications; Prevention

\section{Introduction}

Pregnancy is a vulnerable period for women because of the increased insulin resistance by the placenta diabetogenic effects in order to ensure more available glucose to the fetus (1). Gestational diabetes mellitus (GDM) is a condition defined as any degree of glucose intolerance during pregnancy that resolves postpartum (2). GDM complicates nearly more than $10 \%$ of all pregnancies in the USA and $17 \%$ of pregnancies in Iran (3). During the past 20 years, the prevalence of GDM has increased by 10\%-100\% in several race/ethnicity groups (4). The rise in GDM along with type 2 diabetes (T2D) and obesity worldwide has become of particular concern (5). In different populations and geographical regions, the risk of developing T2D is 7.4 higher among women with GDM in comparison with women without GDM, both postpartum and later in life (6-8). In addition, young women with GDM are at greater risk of developing cardiovascular diseases (CVD) and coronary artery diseases (CAD), much attributable to the development of T2D $(9,10)$. Moreover, there is reportedly increased risk of preeclampsia, asymptomatic bacteriuria, pyelonephritis and cesarean delivery among women with GDM $(11,12)$. Besides the adverse effects of GDM on the mother both in the short and long-terms, GDM was linked with many fetal and neonatal complications including macrosomia (1-16), shoulder dystocia (17), neonatal hypoglycemia (18) and congenital malformation (19-21). 
With $92 \%$ of the global population living in areas not meeting the WHO air quality guidelines levels, ambient (outdoor) air pollution (AAP) is being considered a major risk to the public health (22). In 2012, AAP caused 3 million premature death worldwide, with $88 \%$ of these premature deaths in low and middle-income (LMI) countries (22). AAP was associated with many adverse health conditions including cardiopulmonary disease, lung cancer and acute lower respiratory infection $(23,24)$. In addition, air pollution was significantly associated with insulin resistance and diabetes-related mortality (25-27). This association may be gender-dependent, being more distinct among women than men. (28-31). Although the biological mechanisms underlying this association are still unclear, animal studies have shown that high levels of air pollution may be equivalent to a high-fat diet in terms of its effects, involving immune activation, endoplasmic reticulum (ER) stress, oxidative stress and CNS inflammation $(32,33)$.

Some studies have investigated the association between GDM and air pollutant including nitric oxides $\left(\mathrm{NO}_{\mathrm{x}}\right)$, sulfur dioxide $\left(\mathrm{SO}_{2}\right)$, ozone $\left(\mathrm{O}_{3}\right)$, particulate matter with diameter $\leq 10 \mu \mathrm{m}\left(\mathrm{PM}_{10}\right)$ and particulate matter with diameter $\leq 2.5$ $\left(\mathrm{PM}_{2.5}\right)$. However, the evidence remains controversial and inconsistent (34).

This systematic review and meta-analysis aimed to summarize the current evidence regarding the association between ambient air pollution and gestational diabetes mellitus. In addition, it will help to provide further rationale for improving air quality standard and the public health.

\section{Methods}

\section{Guidelines}

The Meta-analysis of observational studies in epidemiology (MOOSE) statement was used in reporting this meta-analysis (35).

\section{Search Strategy}

The search process was carried out using the following keywords: (gestational diabetes OR pregnancy induced diabetes* OR pregnancy diabetes* OR gestational diabetes* OR GDM) and (air pol- lution OR outdoor air pollution OR ambient air pollution OR traffic pollution OR air pollutants OR outdoor air pollutants OR nitrogen dioxide OR particulate matter OR sulfur dioxide OR Ozone). No language nor publication type filters were used.

\section{Data sources}

An electronic search on PubMed, Embase (via ovidSP), Web of Science, Scopus and Cochrane library databases was conducted from their dates of inception till Oct 2, 2017. Moreover, references of included articles were handsearched for relevant records.

\section{Criteria for selecting studies}

Retrieved records were screened in two steps: title and abstract screening then full-text reviewing. Records were screened for meeting the inclusion criteria: 1) peer-reviewed, published article 2) human population 3) observational study providing data about the association between GDM and AAP 4) levels of air pollutants were monitored. Exclusion criteria were: 1) conference abstracts, editorial, commentaries or reviews 2 ) in vitro or animal study 3) not measuring levels of air pollutants or use proximity to roads as an index for air quality 4) indoor air pollution study.

\section{Data extraction}

A data extraction form was prepared to collect the following data: study ID (first author name, year of publication), country, duration of the study, data source of the study, sample size, number of GDM cases, date of diagnosing GDM, exposure measurement method, investigated pollutants and data type.

\section{Quality assessment}

A modified version of the Newcastle-Ottawa Scale (NOS) for assessing the quality of nonrandomized studies in meta-analyses was used to assess the quality of the included studies (36). Each study could attain a maximum of four points. Studies with $\geq 3$ points were considered of good quality. Those with $\leq 2$ points were considered of poor quality. The scale rated the pa- 
pers according to 1) sample representativeness 2) use of reliable GDM diagnostic method 3) residential-level air quality monitoring 4) adjustment for potential covariates; maternal age and BMI.

\section{Data analysis}

Effect estimates of the included studies were pooled and meta-analyzed using the 'meta' package, $R$ (version 3.4.0) (37). Because most studies used odds ratio (OR) as their effect estimate, the pooled effect estimates were reported as OR with their 95\% confidence interval (CI). Heterogeneity among included studies was tested by the Cochran-Q test and quantified its extent by the Isquare test. When a significant heterogeneity $(P<0.1)$ was found, the pooled effect estimate was calculated under the random-effect model (38). Since included studies reported effect estimate (EE) with different pollutant increments, commonly used standardized increments (10 part per billion (ppb) in $\mathrm{O}_{3}, 10 \mu \mathrm{g} / \mathrm{m}^{3}$ in $\mathrm{PM}_{10}, 10$ $\mu \mathrm{g} / \mathrm{m}^{3}$ in $\mathrm{PM}_{2.5}, 1$ part per million (ppm) in $\mathrm{CO}, 1$ $\mathrm{ppb}$ in $\mathrm{NO}, 10 \mu \mathrm{g} / \mathrm{m}^{3}$ in $\mathrm{NO}_{2}, 1 \mathrm{ppb}$ in $\mathrm{NO}_{\mathrm{x}}$ and $10 \mathrm{ppb}$ in $\mathrm{SO}_{2}$ ) were calculated for each study using the following equation: $\mathrm{EE}_{\text {(standardized) }}=\mathrm{EE}_{\text {(original) }}$ increment $(10) /$ increment(original) $(27,39,40)$. Because the number of the included studies was $<10$, publication bias assessment was not reliable according to Egger and his colleagues (41).

\section{Results}

\section{Study selection}

The search strategy retrieved 247 references. After abstract and full-text reviewing, 8 articles met our inclusion criteria (Fig. 1).

A summary of the included studies was presented in Table 1 (42-49).

- PubMed: 44

- Embase: 55

- Scopus: 61

- Web of Science: 50

- Cochrane database: 7

Total: 217

70 duplicates removed

147 recods identified title and abstract screening

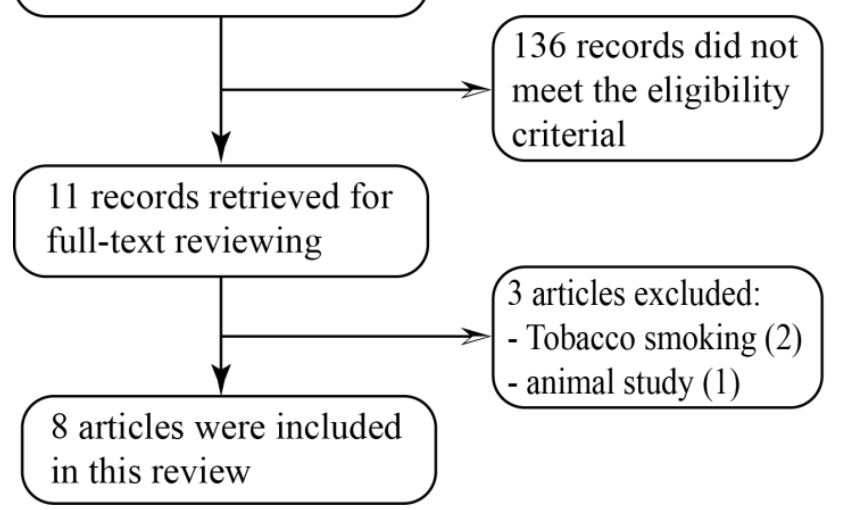

Fig.1: Flow diagram of the search process 
Table 1: Characteristics of the included studies

\begin{tabular}{|c|c|c|c|c|c|c|}
\hline No. & Study ID & Country & Duration & Data sources & Study Size & GDM cases \\
\hline 1 & Pan et al., 2017 (42) & Taiwan & 2005 & Birth Registration Database & 19606 & 378 \\
\hline 2 & M. Pedersen et al., 2017 (43) & Denmark & 1996-2002 & Danish National Birth Cohort & 72745 & 565 \\
\hline 3 & Fleisch et al., 2014 (44) & USA & 1999-2002 & $\begin{array}{l}\text { All Boston-area women at their first } \\
\text { prenatal visit to Harvard Vanguard } \\
\text { Medical Associates were invited }\end{array}$ & 2093 & 118 \\
\hline 4 & Hu et al., 2015 (45) & USA & 2004-2005 & $\begin{array}{c}\text { Bureau of Vital Statistics and Office } \\
\text { of Health Statistics and Assessment, } \\
\text { Florida Department of Health }\end{array}$ & 410267 & 14032 \\
\hline 5 & Malmqvist et al., 2013 (46) & Sweden & $1999-2005$ & Swedish Medical Birth Registry & 81110 & 1599 \\
\hline 6 & Robledo et al., 2015 (47) & USA & $2002-2008$ & $\begin{array}{c}\text { Consortium on Safe Labor (CSL) } \\
\text { cohort study }\end{array}$ & 219952 & 11334 \\
\hline 7 & Fleisch et al., 2016 (48) & USA & $2003-2008$ & $\begin{array}{c}\text { Massachusetts Registry of Vital } \\
\text { Records and Statistics }\end{array}$ & 159373 & 5381 \\
\hline 8 & Yu-Ting Lin et al., 2014 (49) & Taiwan & $2001-2007$ & Taiwanese Birth Registry & 86224 & 2198 \\
\hline
\end{tabular}

Table 1: Continued characteristics

\begin{tabular}{|c|c|c|c|c|c|}
\hline No. & Date of GDM diagnosis* & Exposure measurement & Pollutants** & Data type *** & $\begin{array}{l}\text { Quality } \\
\text { score }\end{array}$ \\
\hline 1 & Week 17 and beyond & $\begin{array}{c}\text { Resident level estimation using } \\
\text { ArcGIS model }\end{array}$ & $\begin{array}{c}\mathrm{PM}_{10}, \mathrm{CO}, \mathrm{NO}, \\
\mathrm{NO}_{2}, \mathrm{NOx}, \mathrm{SO}_{2}, \mathrm{O}_{3}\end{array}$ & $\begin{array}{c}10 \mu \mathrm{g} / \mathrm{m}^{3} \text { increments in } \mathrm{PM}_{10}, 0.1 \\
\mathrm{ppm} \text { in } \mathrm{CO}, 1 \mathrm{ppb} \text { in } \mathrm{NO}, \mathrm{NO}_{2}, \\
\mathrm{NOx}, \mathrm{SO}_{2} \text { and } \mathrm{O}_{3}\end{array}$ & 4 \\
\hline 2 & Week 6-10 & $\begin{array}{c}\text { Pollutant was measured using } \\
\text { address-level AirGIS dispersion } \\
\text { model }\end{array}$ & $\mathrm{NO}_{2}$ & Per $10 \mu \mathrm{g} / \mathrm{m}^{3} \mathrm{NO}_{2}$ & 4 \\
\hline 3 & Second trimester & Residential-level model & $\begin{array}{l}\mathrm{PM}_{2.5} \text { and Black } \\
\text { carbon }\end{array}$ & IQR & 4 \\
\hline 4 & Week 24-28 & $\begin{array}{c}\text { Residential-level model using } \\
\text { ArcGIS model }\end{array}$ & $\mathrm{PM}_{2.5}$ and $\mathrm{O}_{3}$ & $\begin{array}{c}5-\mu \mathrm{g} / \mathrm{m}^{3} \text { increase in } \mathrm{PM}_{2.5}, 5 \mathrm{ppb} \\
\text { increase in exposure to } \mathrm{O}_{3}\end{array}$ & 4 \\
\hline 5 & $\begin{array}{l}\text { During week } 24 \text {, and at week } \\
10 \text { if previous family history } \\
\text { of diabetes or previous diag- } \\
\text { nosis of gestational diabetes }\end{array}$ & $\begin{array}{c}\text { AERMOD model gathering } \\
\text { data from line, point and area } \\
\text { sources linked to woman ad- } \\
\text { dress }\end{array}$ & $\mathrm{NOx}$ & Per quartiles & 3 \\
\hline 6 & Week $24-28$ & $\begin{array}{c}\text { Maternal exposures are based } \\
\text { on the average air pollutant } \\
\text { levels for her delivery hospital } \\
\text { referral region }\end{array}$ & $\begin{array}{c}\mathrm{PM}_{2.5}, \mathrm{CO}, \mathrm{NOx} \\
\mathrm{SO}_{2}, \mathrm{O}_{3}\end{array}$ & IQR & 3 \\
\hline 7 & Week $24-28$ & $\begin{array}{l}\text { Residential-level, satellite-based } \\
\text { spatiotemporal model }\end{array}$ & $\mathrm{PM}_{2.5}$ & $10-90$ percentile range & 4 \\
\hline 8 & Week $24-28$ & $\begin{array}{l}\text { Air quality monitoring stations } \\
\text { using ArcGIS model }\end{array}$ & $\mathrm{O}_{3}$ & $10 \mathrm{ppb}$ for ozone $\left(\mathrm{O}_{3}\right)$ & 3 \\
\hline
\end{tabular}

$*$ Week of gestation

** PM 10: Particulate Matter $\leq 10 \mu \mathrm{m} ; \mathrm{PM}_{2.5}$ : Particulate Matter $\leq 2.5 \mu \mathrm{m}$; CO: Carbon Monoxide; NO: Nitric Oxide; $\mathrm{NO}_{2}$ : Nitric Dioxide; $\mathrm{SO}_{2}$ : Sulfur Dioxide; $\mathrm{O}_{3}$ : Ozone; $\mathrm{NO}_{\mathbf{x}}$ : Nitric Oxides.

*** ppb: part per billion; ppm: part per million

\section{Characteristics of the included studies}

The included studies were carried out in four countries: 4 studies in the USA, 2 in Taiwan, 1 in Sweden and 1 in Denmark. Seven of the included studies were cohort studies with core aim of in- vestigating the association between AAP and GDM (43-49). And, one study was case-control seeking to assess the effect of developing GDM among women giving preterm birth. The sample size ranged from 2093 to 410267. GDM cases in 
the included studies were 35605. Six studies used residential-level exposure measurement to estimate the level of the pollutants (42-46, 48). Women exposure were linked to her hospital referral region. Moreover, air pollutants levels were estimated from some distributed air quality monitoring stations.

\section{Carbon monoxide (CO) (per 1 ppm) and GDM}

Only two studies investigated the association between GDM and CO $(42,47)$. No higher risk of developing GDM was showed during the $1^{\text {st }}$ trimester. However, the association between GDM and $\mathrm{CO}$ were analyzed during the $1^{\text {st }}, 2^{\text {nd }}$ and $3^{\text {rd }}$ trimesters and showed higher odds of GDM during them (Fig. 2). The pooled EE was 1.47 (95\% CI 0.88-2.06). However, there is a high degree of heterogeneity with I-square of $79 \%$. This could be assigned to the difference in the population, sample size, data sources and exposure measurement methods. Data were utilized from a consortium cohort study including 19 hospitals in the USA linking women exposure to her hospital referral region. Whereas data were used from a national birth registration database in Taiwan measuring air pollutants levels at the residential level. In addition, the sample size number of GDM cases were much more in one study than in other. Moreover, the Taiwanese study accounted for many covariates not adjusted in the USA study including pre-pregnancy body mass index (BMI), weight gain, parity, education and household income $(42,47)$.

Nitric oxide (NO) (per 1 ppb) and GDM Only one study investigated the association between NO and GDM. It found significantly high odds of GDM in all trimesters (Fig. 2). The pooled EE was 1.04 (95\% CI 1.03-1.06).

\section{Nitric dioxide $\left(\mathrm{NO}_{2}\right)$ (per $\left.10 \mu \mathrm{g} / \mathrm{m}^{3}\right)$ and GDM}

Two studies assessed the association between $\mathrm{NO}_{2}$ and GDM (Fig. 2) (42, 43). Effect estimate of $\mathrm{NO}_{2}$ were reported during the first trimester only. The overall effect estimate has low degree of heterogeneity (I-square $=43 \%, P=0.16$ ). The pooled EE was 1.01 (95\% CI: 0.95-1.06). Despite that both studies included large sample sizes, used residential-level air monitoring and adjusted for many covariates, there is inconsistency in their $1^{\text {st }}$ trimester results. This could be explained in light of using different GDM diagnostic criteria. A study using the American Diabetes Association criteria; whereas other study used the Danish criteria. Moreover, populations' difference may be due.

\section{Nitric oxides (NO $)_{x}$ (per 1ppb) and GDM}

Three studies reported the association between $\mathrm{NO}_{\mathrm{x}}$ and GDM $(42,46-47)$. All studies showed a slightly positive association between $\mathrm{NO}_{\mathrm{x}}$ and the development of GDM (Fig. 2). The pooled EE was $1.02(95 \%$ CI 1-1.04), I-squared $=91 \%$. In an attempt to clarify the cause of this substantial heterogeneity, each study was removed at a time. When either of the first two studies were removed, substantial heterogeneity still existed (42, 47). However, when the third study was removed, heterogeneity resolved $(P=0.15)$ (46). In each case, the odds of GDM was marginally positive. The difference could be discussed in terms of geographical regions differences and study design. Study (46) was undertaken in Sweden, where air pollutants levels were generally below the WHO air quality guidelines levels. Therefore, the effect of lifetime exposure could attribute the difference. In contrast to third study (46), the first two studies $(42,47)$ studies investigate more than one pollutant in their studies.

\section{Ozone $\left(\mathrm{O}_{3}\right)$ (per $10 \mathrm{ppb}$ ) and GDM}

Four studies included the relationship between $\mathrm{O}_{3}$ and GDM. All studies, but study (42) showed either no or a positive association between $\mathrm{O}_{3}$ and GDM (Fig. 2). The pooled EE was 1.05 (95\% CI 0.94-1.16). However, heterogeneity was substantial with I-squared $=96 \%$. To investigate it, each study was removed at a time. Heterogeneity remained high each time, except when removing study (45) (I-squared=78\%). Despite testing whether the difference in the exposure measurement method, country or by adjusting for season 
of conception could underlie this, heterogeneity remained substantial. The reason behind the decrease in I-squared when $\mathrm{Hu}$ et al., study was removed could be attributed to its sample inclusion and exclusion criteria. Hu et al., applied various exclusion criteria including excluding women whose address could not be geo-coded, preterm birth and births with weight $<400$.

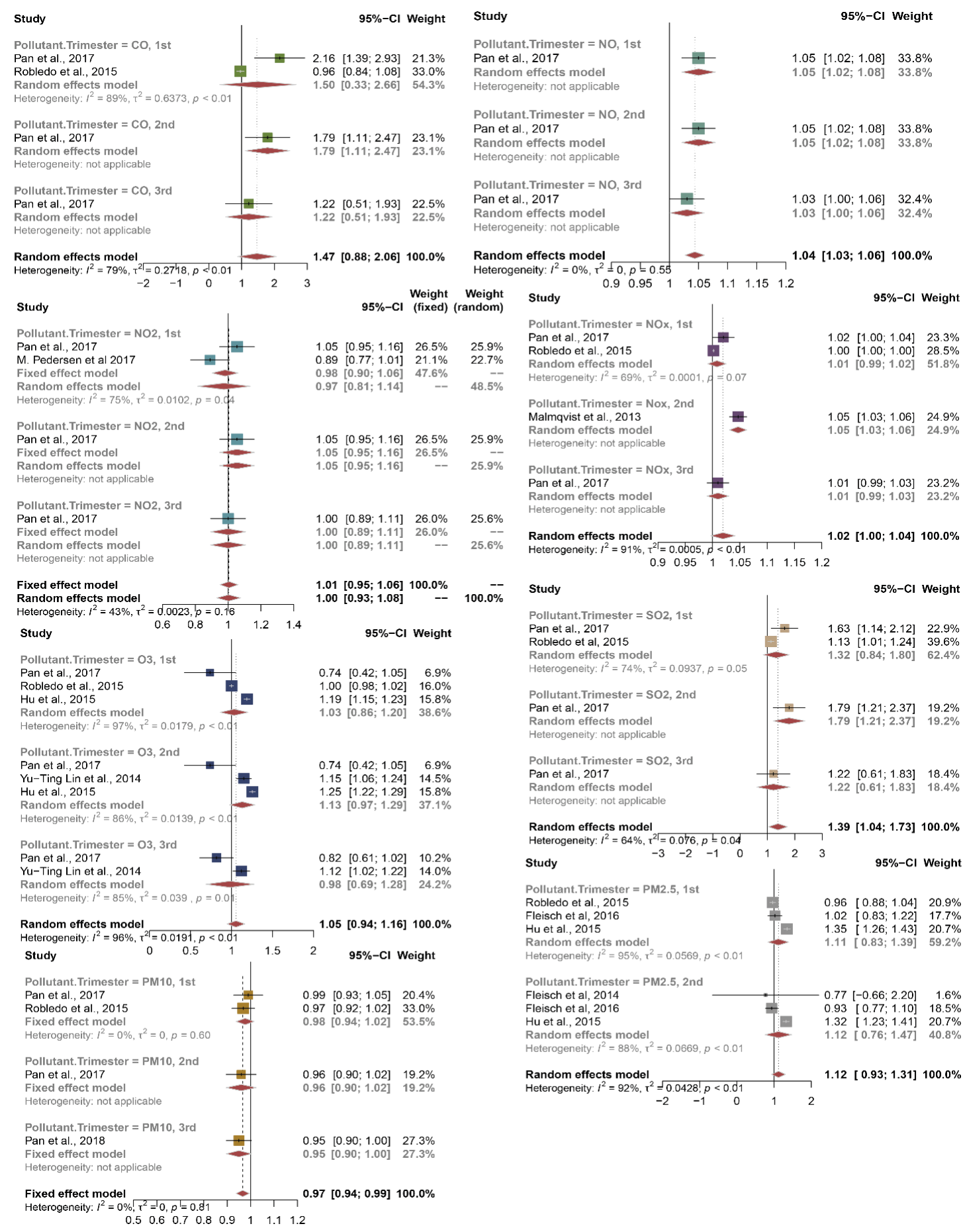

Fig. 2: Forest plot of the association between main outdoor air pollutants and GDM 
Sulfur dioxide $\left(\mathrm{SO}_{2}\right.$ ) (per $10 \mathrm{ppb}$ ) and GDM

Two studies measured and investigated the association between $\mathrm{SO}_{2}$ and GDM $(42,47)$. Both studies showed high odds of GDM in relation to $\mathrm{SO}_{2}$ (Fig. 2). The pooled EE was 1.39 (95\% CI 1.04-1.73), with I-squared $=64 \%$ ). The moderate degree of heterogeneity could be explained by the difference in population, region, data sources and adjustment for covariates. In contrast to study (47), study (42) adjusted its model for BMI, weight gain, and parity.

\section{Particulate Matter $\leq 10 \mu m\left(P M_{10}\right)$ (per 10 $\mu \mathrm{g} / \mathrm{m}^{3}$ ) and $G D M$}

Two studies reported no association between $\mathrm{PM}_{10}$ and the development of GDM (Fig. 2) (42, 47). The pooled EE was 0.97 (95\% CI 0.94-0.99), with I-squared $=0 \%$.

\section{Particulate Matter $\leq 2.5 \mu \mathrm{m}\left(\right.$ PM $\left._{2.5}\right) \quad$ (per 10 $\left.\mu g / m^{3}\right)$ and $G D M$}

Four studies assessed the effect of $\mathrm{PM}_{2.5}$ on developing GDM (Table 1) (44-45, 47-48). The pooled EE was 1.12 (95\% CI 0.93-1.31), with Isquared $=92 \%$ (Fig. 2). When each study was removed at a time, heterogeneity remained, except when removing $\mathrm{Hu}$ et al., study. Upon removing $\mathrm{Hu}$ et al., study the effect estimate showed no association with pooled EE of 0.96 (95\% CI $0.90-0.99)$, with I-squared $=0 \%$. This decrease in the heterogeneity could be explained by the exclusion filters that the $\mathrm{Hu}$ et al., applied other than the other studies. For example, it excluded women with birth $<400$.

\section{Quality assessment}

Using the modified version of the NOS for quality assessment, four studies got a score of four $(42,43,44,46)$, two studies got a score of three $(45,48)$, one study scored two (47) and one study got a score of one (49). Thus, six of the included studies were of good quality, whereas two studies were of poor quality.

\section{Discussion}

This systematic review and meta-analysis included a summary of the current evidence regarding the association between ambient air pollution (AAP) and the development of gestational diabetes mellitus (GDM). The effect estimates of the relationship between GDM and air pollutants ranged from 0.97 (95\% CI 0.94-0.99) for $\mathrm{PM}_{10}$ to 1.47 (95\% CI 0.88-2.06) for CO. However, only $\mathrm{NO}$ and $\mathrm{SO}_{2}$ showed statistically significant effect estimates. In most studies, the second trimester was the most vulnerable period.

Although the biological mechanisms by which AAP contributes to the development of insulin resistance (IR) and glucose intolerance remain unclear, recent experimental and epidemiological have uncovered many insights into the role of AAP-mediated insulin resistance (50). The role of environmental pollutants was evident from the consistent report of the role of persistent organic phosphate pollutants in the development of IR (51-55). In addition, exposure to AAP has been reported to be associated with endothelial dysfunction elevated levels of inflammatory mediators including tumor necrosis factor (TNF) $\alpha$, prostaglandin (PG) E2, C-reactive protein, interleukin-1 $\beta$, and endothelin-1 (56-58). The increased level of inflammation mediator has been shown to interrupt and inhibit insulin signaling and transaction (59-61). Moreover, experimental studies link AAP exposure and endoplasmic reticulum (ER) stress-induced apoptosis in the lung and liver tissue along with brown adipose tissue dysfunction (62-64). ER stress enables the unfolded protein response (UPR) which contributes to the development of IR via inflammation, lipid accumulation, insulin biosynthesis and $\beta$-cell apoptosis (65-68). Thus, the accumulative experimental and epidemiological evidence strongly suggest a biological association between AAP and IR.

\section{Limitations}

Some limitations should be taken into consideration when interpreting the results of this review. First, the number of available studies was limited which may lead to restricting the ability to get a more precise estimate with minimal heterogeneity. Second, two of the included studies did not use residential-level pollutant estimation. Thus, 
this may have led to misclassification of the exact estimate. Finally, most studies have not accounted for many potential covariates and have not applied multipollutant models. Thus, the results of this meta-analysis should be interpreted carefully.

\section{Conclusion}

Some ambient air pollutants may contribute to the development of gestational diabetes mellitus. Reflecting the increasing prevalence of GDM in the context of T2D and obesity necessitates promoting awareness among pregnant women about how air pollution could affect their health and their newborns, especially in regions with limited health care. Besides, this review provides additional evidence about the importance of implementing government-level actions to improve air quality.

\section{Recommendations}

More studies using large, representative sample size and residential-level air monitoring are needed. In addition, they need to take into consideration potential covariates including occupational exposure, indoor air pollution, BMI, ethnicity/race, physical activity, socio-economic background, diet, mother mobility during pregnancy, previous family history of diabetes, and effects of multipollutant rather than one pollutant.

\section{Acknowledgements}

None

\section{Ethical consideration}

Ethical issues (Including plagiarism, informed consent, misconduct, data fabrication and/or falsification, double publication and/or submission, redundancy, etc.) have been completely observed by the author.

\section{Conflict of interest}

The author declares that there is no conflict of interests.

Available at: $\underline{\text { http://ijph.tums.ac.ir }}$

\section{References}

1. Buchanan TA, Xiang AH, Page KA (2012). Gestational diabetes mellitus: risks and management during and after pregnancy. Nat Rev Endocrinol, 8(11):639-49.

2. American Diabetes Association (2010). Standards of medical care in diabetes--2010. Diabetes Care, 33 (Suppl 1):S11-S61.

3. International Diabetes Federation (2017). IDF Diabetes Atlas, 8th edn. Brussels, Belgium: International Diabetes Federation. http://www.diabetesatlas.org

4. Gadgil MD, Oza-Frank R, Kandula NR, et al (2017). Type 2 diabetes after gestational diabetes mellitus in South Asian women in the United States. Diabetes Metab Res Rev, 33(5).

5. Association AD (2016). Management of Diabetes in Pregnancy. Diabetes Care, 39(Supplement 1):S94-8.

6. Chen L, Mayo R, Chatry A, et al (2016). Gestational Diabetes Mellitus: Its Epidemiology and Implication beyond Pregnancy. Curr Epidemiol Rep, 3(1):1-11.

7. Bellamy L, Casas J-P, Hingorani AD, et al (2009). Type 2 diabetes mellitus after gestational diabetes: a systematic review and meta-analysis. Lancet, 373(9677):1773-9.

8. Hopmans T-EJP, van Houten CB, Kasius A, et al (2015). [ncreased risk of type II diabetes mellitus and cardiovascular disease after gestational diabetes mellitus: a systematic review]. Ned Tïdschr Geneesked, 159:A8043.

9. Shostrom DCV, Sun Y, Oleson JJ, et al (2017). History of Gestational Diabetes Mellitus in Relation to Cardiovascular Disease and Cardiovascular Risk Factors in US Women. Front Endocrinol (Lausanne), 8:144.

10. Shah BR, Retnakaran R, Booth GL (2008). Increased Risk of Cardiovascular Disease in Young Women Following Gestational Diabetes Mellitus. Diabetes Care, 31(8):1668-9.

11. Gilmartin A "Bird" H, Ural SH, Repke JT (2008). Gestational Diabetes Mellitus. Rev Obstet Gynecol, 1(3):129-34.

12. Inocêncio $G$, Braga $A$, Lima $T$, et al (2015). Which Factors Influence the Type of Delivery and Cesarean Section Rate in Women with Gestational Diabetes? J Reprod Med, 60(11-12):529-34. 
13. Morgan K, Rahman M, Atkinson M, et al (2013). Association of diabetes in pregnancy with child weight at birth, age 12 months and 5 years--a population-based electronic cohort study. PLoS One, 8(11):e79803.

14. Retnakaran R, Ye C, Hanley AJG, et al (2012). Effect of maternal weight, adipokines, glucose intolerance and lipids on infant birth weight among women without gestational diabetes mellitus. CMAJ, 184(12):1353-60.

15. HAPO Study Cooperative Research Group, Metzger BE, Lowe LP, et al (2008). Hyperglycemia and adverse pregnancy outcomes. $N$ Engl J Med, 358(19):1991-2002.

16. HAPO Study Cooperative Research Group (2009). Hyperglycemia and Adverse Pregnancy Outcome (HAPO) Study: associations with neonatal anthropometrics. Diabetes, 58(2):453-9.

17. Young BC, Ecker JL (2013). Fetal macrosomia and shoulder dystocia in women with gestational diabetes: risks amenable to treatment? Curr Diab Rep, 13(1):12-8.

18. Metzger BE, Persson B, Lowe LP, et al (2010). Hyperglycemia and adverse pregnancy outcome study: neonatal glycemia. Pediatrics, 126(6):e1545-1552.

19. Balsells M, García-Patterson A, Gich I et al. (2012). Major congenital malformations in women with gestational diabetes mellitus: a systematic review and meta-analysis. Diabetes Metab Res Rev, 28(3):252-7.

20. Zhao E, Zhang Y, Zeng X, et al (2015). Association between maternal diabetes mellitus and the risk of congenital malformations: A metaanalysis of cohort studies. Drug Discov Ther, 9(4):274-81.

21. Mitanchez D, Yzydorczyk C, Simeoni U (2015). What neonatal complications should the pediatrician be aware of in case of maternal gestational diabetes? World J Diabetes, 6(5):734 43.

22. WHO (2018). Ambient (outdoor) air quality and health [Internet]. WHO.

23. Taj T, Malmqvist E, Stroh E, et al (2017). ShortTerm Associations between Air Pollution Concentrations and Respiratory HealthComparing Primary Health Care Visits, Hospital Admissions, and Emergency Department Visits in a Multi-Municipality Study. Int J Environ Res Public Health, 14(6): E587.
24. Brunekreef B, Beelen R, Hoek G, et al (2009). Effects of long-term exposure to trafficrelated air pollution on respiratory and cardiovascular mortality in the Netherlands: the NLCS-AIR study. Res Rep Health Eff Inst, (139):5-71; discussion 73-89.

25. Meo SA, Memon AN, Sheikh SA, et al (2015). Effect of environmental air pollution on type 2 diabetes mellitus. Eur Rev Med Pharmacol Sci, 19(1):123-8.

26. Brook RD, Cakmak S, Turner MC, et al (2013). Long-Term Fine Particulate Matter Exposure and Mortality from Diabetes in Canada. Diabetes Care, 36(10):3313-20.

27. Li C, Fang D, Xu D, et al (2014). Mechanisms in endocrinology: main air pollutants and diabetes-associated mortality: a systematic review and meta-analysis. Eur $J$ Endocrinol, 171(5):R183-90.

28. SOHN D, OH H (2017). Gender-dependent Differences in the Relationship between Diabetes Mellitus and Ambient Air Pollution among Adults in South Korean Cities. Iran J Public Health, 46(3):293-300.

29. Coogan PF, White LF, Jerrett M, et al (2012). Air pollution and incidence of hypertension and diabetes mellitus in black women living in Los Angeles. Circulation, 125(6):767-72.

30. Brook RD, Jerrett M, Brook JR, et al (2008). The relationship between diabetes mellitus and traffic-related air pollution. J Occup Environ Med, 50(1):32-8.

31. Choi Y-H, Kim JH, Hong Y-C (2015). Sexdependent and body weight-dependent associations between environmental PAHs exposure and insulin resistance: Korean urban elderly panel. J Epidemiol Community Health, 69(7):625-31.

32. Rao X, Patel P, Puett R, et al (2015). Air Pollution as a Risk Factor for Type 2 Diabetes. Toxicol Sci, 143(2):231-41.

33. Kodavanti UP (2015). Air Pollution and Insulin Resistance: Do All Roads Lead to Rome? Diabetes, 64(3):712-4.

34. Farah H, Nawaz M, Sabra R (2016). Exposure to air pollution and risk of gestational diabetes mellitus

(GDM). http://ruor.uottawa.ca/handle/10393/35550

35. Manchikanti L, Datta S, Smith HS, et al (2009). Evidence-based medicine, systematic reviews, and guidelines in interventional pain man- 
agement: part 6. Systematic reviews and metaanalyses of observational studies. Pain Physician, 12(5):819-50.

36. Ottawa Hospital Research Institute [Internet]. http://www.ohri.ca/programs/clinical_epide miology/oxford.asp

37. Schwarzer G. meta: General Package for MetaAnalysis [Internet]. 2017. https://cran.rproject.org/web/packages/meta/index.html

38. Cochrane Handbook for Systematic Reviews of Interventions [Internet]. http://handbook-51.cochrane.org/

39. Siddika N, Balogun HA, Amegah AK (2016). Prenatal ambient air pollution exposure and the risk of stillbirth: systematic review and meta-analysis of the empirical evidence. Occup Environ Med, 73(9):573-81.

40. Shah AS, Langrish JP, Nair H, et al (2013). Global association of air pollution and heart failure: a systematic review and meta-analysis. Lancet, 382(9897):1039-48.

41. Leucht S, Kissling W, Davis JM (2009). How to read and understand and use systematic reviews and meta-analyses. Acta Psycbiatr Scand, 119(6):443-50.

42. Pan S-C, Huang C-C, Lin S-J, et al (2017). Gestational diabetes mellitus was related to ambient air pollutant nitric oxide during early gestation. Environ Res, 158:318-23.

43. Pedersen M, Olsen SF, Halldorsson TI, et al (2017). Gestational diabetes mellitus and exposure to ambient air pollution and road traffic noise: A cohort study. Environ Int, 108:253-60.

44. Fleisch AF, Gold DR, Rifas-Shiman SL, et al (2014). Air Pollution Exposure and Abnormal Glucose Tolerance during Pregnancy: The Project Viva Cohort. Emiron Health Perspect,122(4):378-83.

45. Hu H, Ha S, Henderson BH, et al (2015). Association of Atmospheric Particulate Matter and Ozone with Gestational Diabetes Mellitus. Environ Health Perspect, 123(9):853-9.

46. Malmqvist E, Jakobsson $\mathrm{K}$, Tinnerberg $\mathrm{H}$, et al (2013). Gestational Diabetes and Preeclampsia in Association with Air Pollution at Levels below Current Air Quality Guidelines. Environ Health Perspect, 121(4):488-93.

47. Robledo CA, Mendola P, Yeung E, et al (2015). Preconception and early pregnancy air pollu- tion exposures and risk of gestational diabetes mellitus. Environ Res, 137:316-22.

48. Fleisch AF, Kloog I, Luttmann-Gibson $\mathrm{H}$, et al (2016). Air pollution exposure and gestational diabetes mellitus among pregnant women in Massachusetts: a cohort study. Environ Health, 15:40.

49. Lin Y-T, Jung C-R, Lee YL, et al (2015). Associations between ozone and preterm birth in women who develop gestational diabetes. $A m$ J Epidemiol, 181(4):280-7.

50. Rajagopalan S, Brook RD (2012). Air Pollution and Type 2 Diabetes: Mechanistic Insights. Diabetes, 61(12):3037-45.

51. Ruzzin J, Petersen R, Meugnier E, et al (2010). Persistent Organic Pollutant Exposure Leads to Insulin Resistance Syndrome. Environ Health Perspect, 118(4):465-71.

52. Tillett T (2010). Chew on This: Persistent Organic Pollutants May Promote Insulin Resistance Syndrome. Environ Health Perspect, 118(4):A173.

53. Ngwa EN, Kengne A-P, Tiedeu-Atogho B, et al (2015). Persistent organic pollutants as risk factors for type 2 diabetes. Diabetol Metab Syndr, 7:41.

54. Jaacks LM, Staimez LR (2015). Association of persistent organic pollutants and nonpersistent pesticides with diabetes and diabetes-related health outcomes in Asia: A systematic review. Environ Int, 76:57-70.

55. Mostafalou S (2016). Persistent Organic Pollutants and Concern Over the Link with Insulin Resistance Related Metabolic Diseases. Rev Environ Contam Toxicol, 238:69-89.

56. Calderón-Garcidueñas L, Villarreal-Calderon R, Valencia-Salazar G, et al (2008). Systemic Inflammation, Endothelial Dysfunction, and Activation in Clinically Healthy Children Exposed to Air Pollutants. Inhal Toxicol, 20(5):499-506.

57. Achilleos S, Kioumourtzoglou M-A, et al (2017). Acute effects of fine particulate matter constituents on mortality: A systematic review and meta-regression analysis. Environ Int, 109:89-100.

58. Niemann B, Rohrbach S, et al (2017). Oxidative Stress and Cardiovascular Risk: Obesity, Diabetes, Smoking, and Pollution: Part 3 of a 3Part Series. J Am Coll Cardiol, 70(2):230-51. 
59. de Luca C, Olefsky JM (2008). Inflammation and Insulin Resistance. FEBS Lett, 582(1):97-105.

60. Fuentes L, Rőszer T, Ricote M (2010). Inflammatory Mediators and Insulin Resistance in Obesity: Role of Nuclear Receptor Signaling in Macrophages. Mediators Inflamm, 2010:219583.

61. Chen L, Chen R, Wang H, et al (2015). Mechanisms Linking Inflammation to Insulin Resistance. Int J Endocrinol, 2015: 508409.

62. Liu C, Ying Z, Harkema J, et al (2013). Epidemiological and Experimental Links between Air Pollution and Type 2 Diabetes. Toxicol Pathol, 41(2):361-73.

63. Laing S, Wang G, Briazova T, et al (2010). Airborne particulate matter selectively activates endoplasmic reticulum stress response in the lung and liver tissues. Am J Physiol Cell Physiol, 299(4):C736-749.

64. Velasco G (2010). Endoplasmic reticulum stressed by pollution. Focus on "Airborne particulate matter selectively activates endoplasmic reticulum stress response in the lung and liver tissues." Am J Physiol Cell Physiol, 299:C727-8.

65. Salvadó L, Palomer X, Barroso E, et al (2015). Targeting endoplasmic reticulum stress in insulin resistance. Trends Endocrinol Metab, 26(8):438-48.

66. Boden G (2009). Endoplasmic Reticulum Stress: Another Link Between Obesity and Insulin Resistance/Inflammation? Diabetes, 58(3):5189.

67. Jeschke MG, Finnerty CC, Herndon DN, et al (2012). Severe injury is associated with insulin resistance, endoplasmic reticulum stress response, and unfolded protein response. Ann Surg, 255(2):370-8.

68. Kim O-K, Jun W, Lee J (2015). Mechanism of ER Stress and Inflammation for Hepatic Insulin Resistance in Obesity. Ann Nutr Metab, 67(4):218-27. 